\title{
Prevalence of reproductive morbidity and its determinants among ever married women of reproductive age group (15-45 years) in a rural area of Kozhikode
}

\author{
Sajna M V. ${ }^{1 *}$, Bina T. ${ }^{2}$, Rahael L. ${ }^{3}$ \\ DOI: https://doi.org/10.17511/ijphr.2017.i2.05
}

\author{
1* Sajna M V, Assistant Professor, Department of Community Medicine, Government Medical College, Thrissur, Kerala, India. \\ 2 Thomas Bina, Professor and Head, Government Medical College, Kozhikode, Kerala, India. \\ 3 Lucy Rahael, Former Professor and Head, Government Medical College, Thrissur, Kerala, India.
}

\begin{abstract}
Background: Reproductive ill health contributes about $20 \%$ of global burden of ill health among women. To achieve the goal of universal access to reproductive health, the burden of the illness and their risk factors should be assessed in different areas Objectives: To study the prevalence and association of demographic and other factors with self reported reproductive morbidity among married women of reproductive age group; 15- 45 years Methodology: A cross sectional study was conducted among 600 ever married females in the field practice area of Department of Community Medicine. Cluster sampling method was adopted. Using structured schedule, interview of the selected female from one house was conducted by the same female investigator. Data analysed using SPSS 16. Results: 378 (63\%) of the women were in the age between 20-35 years. Mean age of the women was $31.5+0.7 .6$ years. Prevalence of reproductive morbidity was $30.5 \%$ ( $95 \% \mathrm{CI}$ $26 \%$ - 34.99\%). 167 (27.8\%) women had gynecological morbidity, and 8 women had obstetric morbidity i.e. $1.3 \%$ and prevalence of contraceptive morbidity was 8 (1.3\%). Conclusion: Reproductive health problems are prevalent in this community. More than one fourth of the women reported at least one type of gynaecological morbidity which is a high prevalence. Socio demographic factors have some role in the prevalence of reproductive morbidity such as age, religion, occupation, housing standards, socio economic status, co habitation status. Others included early age at menarche, early age at marriage, bad obstetric history, increased parity, history of menstrual abnormality and poor nutritional status.
\end{abstract}

Keywords: Reproductive morbidity, National family health survey, District level house hold survey, World Health Organization, Cluster sampling

Corresponding Author

Sajna M V, Assistant Professor, Department of Community Medicine, Government Medical College, Thrissur, Kerala, India. Email: mvsajna@yahoo.com

\section{How to Cite this Article}

Sajna M V, Bina T, Rahael L. Prevalence of reproductive morbidity and its determinants among ever married women of reproductive age group (1545 years) in a rural area of Kozhikode. Public Health Rev Int J Public Health Res. 2017;4(2):59-70. Available From https://publichealth.medresearch.in/index.php/ijphr/ article/view/63
To Browse

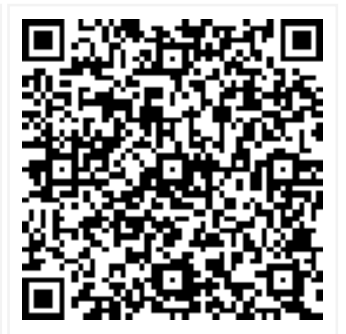

Manuscript Received 2017-04-04

Conflict of Interest No

(c) 2017 by Sajna M V, Thomas Bina, Lucy Rahael and Published by Siddharth Health Research and Social Welfare Society. This

Review Round 1
2017-04-14
Funding
Nil

Review Round 2
2017-04-23
$\begin{gathered}\text { Ethical Approval } \\ \text { Yes }\end{gathered}$

Review Round 3

Accepted 2017-04-30

Plagiarism $\mathbf{X}$-checker $8 \%$

Note is an Open Access article licensed under a Creative Commons Attribution 4.0 International License https://creativecommons.org/licenses/by/4.0/ unported [CC BY 4.0]. 


\section{Introduction}

Reproductive and sexual health is fundamental to individuals, couples and families, and the social and economic development of communities and nations. The slogan "Healthy women, Healthy World" implies that women play a critical role in maintaining the health and well being of their family as well as their community [1].

Women suffer silently from a large number of reproductive illnesses called as silent epidemic [2]. Reproductive and sexual ill-health such as maternal and perinatal mortality and morbidity, cancers, sexually transmitted infections and HIV/AIDS account for nearly $20 \%$ of the global burden of illhealth for women [3].

The World Health Organization (WHO) estimates that about 30-60 million women suffer severe illness as a result of serious maternal complications and about one third of women in developing countries suffer from such morbidity [4].

In 2004, the World Health Assembly renewed the commitment of the international community to sexual and reproductive health by adopting "a global reproductive health strategy" (world health resolution).

Reproductive morbidity is defined as -any morbidity or dysfunction of the reproductive tract or any morbidity which is a consequence of reproductive behaviours including pregnancy, contraceptive use, abortion, child birth, or sexual behaviour. The morbidity can broadly be divided into 3 categories, as Obstetric morbidity, Contraceptive morbidity and Gynaecological morbidity [5].

It has been observed that there are marked differences in the prevalence and pattern of reproductive morbidity among the women throughout the country. The percentage of currently married women with any reproductive health problem varies from $19 \%$ in Karnataka to $67 \%$ in Meghalaya [6]. The prevalence of reproductive morbidity among married females in Kerala was 42.4\% (NFHS2) [6].

The District Level House hold Facility survey 3 conducted by Ministry of Health and Family Welfare reported that $12.1 \%$ married women had symptoms suggestive of reproductive tract infections in Kerala and around $77.6 \%$ of rural women are aware of the symptoms of reproductive infections [7].
In order to achieve the goal of universal access to reproductive health, the burden of the illness and their risk factors should be assessed in different areas so that specific intervention strategies can be adopted accordingly.

Hence a study on the prevalence and risk factors of reproductive morbidity among the married women in a rural area of the Kozhikode district will provide valuable data on the common reproductive health problems that require immediate attention through health programmes, can also help to suggest modifications in the existing programmes.

The present study was conducted in the Mavoor Panchayat, the rural field practice area of the Dept Community Medicine, Calicut Medical College, Kerala. The data thus generated can also be used for planning more comprehensive reproductive health strategies for management and control of reproductive morbidity in the community.

\section{Objectives}

01. To study the prevalence of self reported reproductive morbidity- obstetric, gynecological and contraceptive, among married women of reproductive age group; $15-45$ years

02. To study the association of demographic and other factors with self reported reproductive morbidity

\section{Methodology}

This was a community based cross sectional study. Kozhikode District is situated in the northern part of Kerala. The study was conducted in Mavoor Grama Panchayat, which is one of the field practice areas of Medical College Health unit Cheruppa, a block PHC, in the district.

The study was conducted over a period of one year. Data collected was done over a period of 3 months from January 2009 to March 2009.

The study subjects included all the married women of 15- 45 years permanently residing in the Mavoor Panchayat during the study period. All currently married and ever married women of the age group 15-45 years who were the permanent residents in Mavoor Panchayat area for a period of at least 6 months who gave consent to participate in the study were included.

Sample size was calculated using the formula $n=$ $4 \mathrm{pq} / \mathrm{d} 2$. 
Prevalence of gynaecological morbidity was 36\% in a study by Bhatia JC et al (8) in South India in 1997 As the cluster sampling method was used the design effect (D) was taken into account. With an allowable error of $15 \%$ and design effect of 2 the sample size calculated was 632 .

Cluster sampling method was used for the study. Sub centers areas in Mavoor Panchayat were used as clusters. There were 5 sub center areas in Mavoor Panchayat. Each sub center area was considered as one cluster. For better representation all clusters were included for the study. House hold in the cluster was considered as the primary sampling unit. Hence women from all the clusters were studied.

To obtain the required sample size from the clusters, 126 subjects were included in each cluster. It was decided to take one married female from one household. Allowing a dropout rate of $10 \%$ for non availability, non cooperation to a total of 140 houses was included from each sub center area.

From the main bus stop in each ward the different roads originating were enumerated and one of the roads was selected randomly. By simple random method one of the houses situated on that road was selected as the first house.

The next house to be selected for the study was that closest to the first house on the same side of the road and so on till 140 consecutive houses were selected in each sub center area. In case the road was terminated, houses on the opposite road or street were continued. There were 640 eligible subjects in the 750 households.

Eligible subjects in the selected house hold were identified and informed regarding the purpose of the study. If more than one eligible subject was there, then one person was selected using Kish table method. Kish table is a type of random table used to select one individual from eligible persons in the house hold.

After the selection of woman, informed consent was obtained and the data was collected by Interview method using pretested semi structured schedule and general \& systemic examination. Houses were pre informed and the interview was conducted in the day time for better compliance.

Self reported reproductive morbidity was assessed by interview method using pre tested semi structured oral questionnaire.
The reproductive morbidity can broadly be divided into 3 categories, as Obstetric morbidity, Contraceptive morbidity and Gynaecological morbidity [9]. Diagnosis of morbidity was by operational definitions made based on the algorithmic syndromic approach.

All the women were interviewed by the same female investigator with sufficient privacy. Medical documents were used wherever available to support the diagnosis. At least two extra visits were made in households where subjects could not be contacted to increase the response rate. Socioeconomic status was assessed using Modified Udai Parikh scale [10].

Analysis: All the data were coded and entered in Microsoft Excel sheet rechecked and analyzed using SPSS statistical software. Prevalence of reproductive morbidities among the study population was measured using proportion. 95\% Confidence interval of the prevalence was calculated using standard error. The association of the risk factors with the morbidity was done using chi square test. Regression analysis was done for multivariate analysis. Statistical comparison was done using $t$ tests and tests of proportions and the level of significance was estimated with $95 \%$ confidence interval and $\mathrm{p}$ value.

Ethical Aspects: The study protocol was submitted to the Scientific Research Committee as well as Institutional Ethics Committee of Govt Medical College, Calicut and clearance was obtained for conducting the study. Informed consent was obtained from all the study participants. All the information that is collected was kept confidential. Specific disease identified during the study was conveyed to the participants and necessary medical advice given. Awareness regarding the reproductive health problems was given to all of the subjects.

\section{Results}

Out of the 640 eligible subjects, 600 women participated in the study. The overall response rate was $93.8 \%$. Women were distributed evenly in this study except in the extreme age groups. Mean age of the women was $31.5 \pm 7.6$ years ( $17-45$ years).

The religious distribution of the study population composed predominantly of Muslims 385(64.2\%) others were Hindus 208(34.7\%) and Christians $7(1.2 \%)$. In this study $537(89.5 \%)$ women were literate which is comparable to female literacy rate of Kerala of $90.92 \%$ and of Kozhikode $88.6 \%$ and only $2(0.3 \%)$ were illiterate. 
Majority of the women, 535 (89.2\%) in the study group were house wives. Socio economic status of the study population was assessed using Modified Udai Parikh scale. In 65(10.8\%) houses there was overcrowding. Among the study women 591(98.5\%) were currently married, 7 (1.2\%) were widows, $1(0.2 \%)$ divorcee and $1(0.2 \%)$ separated women.

The present study showed that 473 (78.8\%) women were co habitating with their husbands currently. Mean age at marriage in the study group is $19.3+$ 2.9 (Range- 13 to 35 years), lower than that of Kerala. Socio-demographic details are given detail in the table no 1 .

Table No.-1: Distribution according to sociodemography

\begin{tabular}{|c|c|}
\hline Variable & No $=600(\%)$ \\
\hline \multicolumn{2}{|l|}{ 1. Age } \\
\hline $15-19$ & $33(5.5)$ \\
\hline 20-24 & $120(20)$ \\
\hline $25-29$ & 146 (24.3) \\
\hline 30-34 & $112(18.7)$ \\
\hline $35-39$ & 105 (17.5) \\
\hline $40-45$ & $84(14)$ \\
\hline \multicolumn{2}{|l|}{ 2. Educational status } \\
\hline Illiterate & $2(0.3)$ \\
\hline $1-10$ years of schooling & $383(63.8)$ \\
\hline Pre degree & $149(24.8)$ \\
\hline Degree & $62(10.3)$ \\
\hline Professional & $4(0.7)$ \\
\hline \multicolumn{2}{|l|}{ 3. Occupational status } \\
\hline House wife & $535(89.2)$ \\
\hline Teacher & $18(3)$ \\
\hline Semi skilled & $16(2.7)$ \\
\hline Skilled & $13(2.2)$ \\
\hline Office work & $7(1.2)$ \\
\hline Health worker & $2(0.4)$ \\
\hline Unskilled & $5(0.8)$ \\
\hline Professional & $4(0.7)$ \\
\hline \multicolumn{2}{|l|}{ 4. Socioeconomic status } \\
\hline High & $12(2)$ \\
\hline Middle & $382(64)$ \\
\hline Low & $206(34)$ \\
\hline
\end{tabular}

Table No-2: Prevalence of reproductive morbidity among the population

\begin{tabular}{|l|l|l|l|}
\hline \multicolumn{1}{|c|}{ Type of morbidity } & No & \multicolumn{1}{c|}{$\%(\mathrm{n}-600)$} & \multicolumn{1}{c|}{$95 \% \mathrm{CI}$} \\
\hline Gynaecological morbidity & 167 & 27.8 & $23.42-32.17$ \\
\hline Obstetric morbidity & 8 & 1.3 & $0.19-2.45$ \\
\hline Contraceptive morbidity & 8 & 1.3 & $0.19-2.45$ \\
\hline Total Reproductive morbidity & 183 & 30.5 & $26.00-34.99$ \\
\hline
\end{tabular}

Table No-3: Prevalence of gynaecological morbidity among the study population

\begin{tabular}{|l|c|l|l|}
\hline \multicolumn{1}{|c|}{ Gynaecological morbidity } & No & Percentage (600) & 95\% CI \\
\hline Reproductive tract infections & 63 & 10.5 & $7.50-13.49$ \\
\hline UTI & 49 & 8.2 & $5.52-10.87$ \\
\hline Stress incontinence & 24 & 4 & $2.08-5.91$ \\
\hline PID & 8 & 1.3 & $0.194-2.40$ \\
\hline Menstrual problem(Dysmenorrhoea) & 3 & 0.5 & $-0.18-1.18$ \\
\hline Prolapse & 2 & 0.3 & $-0.233-0.83$ \\
\hline Dyspareunia & 1 & 0.2 & $-0.23-0.63$ \\
\hline
\end{tabular}

Table No-4: Association of risk factors with reproductive morbidity - univariate analysis

\begin{tabular}{|c|c|c|c|}
\hline \multicolumn{2}{|r|}{ Factor } & \multirow{2}{*}{\begin{tabular}{|c|}
$\begin{array}{c}\text { Odds } \\
\text { ratio }\end{array}$ \\
1.74
\end{tabular}} & \multirow{2}{*}{\begin{tabular}{|l}
$95 \%$ CI \\
$0.80-$ \\
3.73
\end{tabular}} \\
\hline Age & $15-19$ years Vs $20-45$ years & & \\
\hline Education & $\begin{array}{l}<7 \text { years schooling Vs }>7 \\
\text { years schooling }\end{array}$ & 0.84 & $0.87-1.5$ \\
\hline Religion & Non Muslim Vs Muslim & 1.37 & $0.95-2$ \\
\hline Occupation & Unemployed Vs Employed & 1.16 & $\begin{array}{l}0.654- \\
2.066\end{array}$ \\
\hline Overcrowding & Present Vs Absent & 1.61 & $\begin{array}{l}0.91- \\
2.81\end{array}$ \\
\hline *Water source & Public Vs Own & 2.31 & $\begin{array}{l}1.17- \\
4.58\end{array}$ \\
\hline Cohabitation & $\begin{array}{l}\text { Staying together Vs Not } \\
\text { staying together }\end{array}$ & 1.384 & $0.8-2.18$ \\
\hline Age at marriage & $<18$ years $V s>18$ years & 0.94 & $\begin{array}{l}0.64- \\
1.34\end{array}$ \\
\hline *Parity & $\begin{array}{l}\text { Less than two Vs More than } \\
\text { two }\end{array}$ & 1.5 & $\begin{array}{l}1.04- \\
2.15\end{array}$ \\
\hline \multirow[t]{2}{*}{ Contraceptive method } & Condom Vs Non users & 0.64 & $\begin{array}{l}0.32- \\
1.28\end{array}$ \\
\hline & IUD Vs Tubecctomy & 1.84 & $0.4-8.18$ \\
\hline $\begin{array}{l}\text { *Abnormal menstrual } \\
\text { history }\end{array}$ & Present Vs Absent & 1.4 & $1.1-2.01$ \\
\hline *History of abortion & Present Vs Absent & 1.7 & $\begin{array}{l}1.15- \\
2.63\end{array}$ \\
\hline $\begin{array}{l}\text { *History of antenatal } \\
\text { complications }\end{array}$ & Present Vs Absent & 1.8 & $\begin{array}{l}1.15- \\
3.11\end{array}$ \\
\hline *BMI & $<25$ Vs $>25$ & 2.1 & $\begin{array}{l}1.13- \\
3.61\end{array}$ \\
\hline
\end{tabular}

Table No-5: Association of risk factors with reproductive morbidity-multivariate analysis

\begin{tabular}{|l|l|l|}
\hline \multicolumn{1}{|c|}{ Factor } & Odds ratio & $95 \%$ CI \\
\hline History of abortion Present Vs absent & 1.60 & $0.983-2.62$ \\
\hline Histoy ofantenatal complications Present Vs absent & 1.62 & $0.92-2.8$ \\
\hline Water source- Public Vs own & 0.980 & $0.59-1.6$ \\
\hline Parity -Less than two Vs More than two & 1.23 & $0.83-1.8$ \\
\hline BMI $-<25$ Vs $>25$ & 2.16 & $1.2-3.8$ \\
\hline
\end{tabular}




\section{Reproductive Events}

Menstrual cycles: Mean age at menarche was $13.79 \pm 0.935$ years which was in the normal age group of 12-14 years [11]. Among the women, $255(42.5 \%)$ reported history of at least one menstrual abnormality. Among the menstrual abnormalities the most commonly reported one was dysmenorrhoea i.e. 174 (68.2\%), followed by hypomenorrhoea $27(10.5 \%)$, menorrhagia $18(7 \%)$, oligomenorrhoea $14(5.4 \%)$. In the study group $10.2 \%$ i.e. 61 women were having amenorrhoea.

Obstetric events: In obstetric history, 438 (73\%) of the women had only normal deliveries, $60(10 \%)$ had only caesarian section and $8(1.3 \%)$ women had both. Among the women 162(27\%) had history of at least one complication due to pregnancy and delivery. Pregnancy induced hypertension and anemia were the most common complications in the ante natal period.

Post-partum hemorrhage and infection were the major complications in the post-partum period.

Contraceptive details: Among the study participant, $322(53.6 \%)$ adopted a method of family planning currently. The most commonly adopted method was tubectomy $234(72.7 \%)$, followed by condom 61(18.9\%). 8 (1.3\%) women had complications due to family planning methods. The complications were bleeding and low back ache.

\section{Prevalence of reproductive morbidity}

Among the women 183 had at least one type of reproductive morbidity. Prevalence of reproductive morbidity was $30.5 \%$ (95\% CI $26 \%$ - 34.99\%). Among the morbidity, 167 (27.8\%) women had gynaecological morbidity, and 8 women had obstertic morbidity i.e. $1.3 \%$ and prevalence of contraceptive morbidity was $8(1.3 \%)$. Reproductive tract infections $(10.5 \%)$, Urirary tract infection $(8.2 \%)$, Stress incontinence $(4 \%), \operatorname{PID}(1.3 \%)$ were the major Gynaecological morbidities (Table 3). $4.3 \%$ had chronic type of Gynaecological morbidity (>3months). In women with Gynaecological morbidity, 24(14.4\%) had more than one episode of the illness. Prevalence is given in detail in the table number 2. Pregnancy induced hypertension, Gestational diabetes, Caesarian section, intrauterine death were the reported obstetric morbidity in this study. Low back ache ( 5 persons), bleeding ( 2 in no) and had post operative infection followed by tubectomy were the reported contraceptive morbidity.

\section{Risk factors of reproductive morbidity}

Background factors: Reproductive morbidity was high $(42.4 \%)$ in the age less than 19 years. The prevalence of the morbidity was not significantly different at various educational levels of the women. There was a lesser prevalence of morbidity found out among the Muslim women $(28.1 \%)$ when compared with Non Muslim women (34.9\%). The prevalence of the morbidity was lesser in women who were employed $(27.1 \%)$ than who were not employed (30.8\%).

Socioeconomic factors: There is not much difference in the prevalence of reproductive morbidity among different socio economic status (low SES- 30.1\%, middle and high SES- 30.7\%) . $40 \%$ of the women with overcrowding had morbidity while only $29.3 \%$ of women without overcrowding had morbidity. The prevalence was $31.7 \%$ in those who were staying together with their husband currently and $25.2 \%$ who were not. There was significantly higher prevalence of reproductive morbidity in women who used public water source $(48.7 \%)$ than own water source $(29.2 \%)$.

Intermediate factors: In this study there is not much difference in the prevalence of morbidity in women whose age at marriage was below 18 years (30.1\%) and above (31.3\%) 18 years. $35.2 \%$ of those with more than two deliveries and $26.6 \%$ of those with less than two deliveries reported morbidity. The prevalence was high among IUD users $(44.4 \%)$ and low among condom users $(23 \%)$.

Medical risk factors: There was significantly higher prevalence in women who reported history of menstrual abnormality (34.9\% with history and $27.2 \%$ without history) and with antenatal complications (with antenatal complications $43.2 \%$ and without $28.7 \%$ ). Women with history of abortion had higher prevalence of reproductive morbidity ( $40.4 \%$ with abortion and $28.3 \%$ without abortion).

The prevalence of reproductive morbidity in the women with BMI less than 18.5, was significantly high (41.6\%) than with BMI 18.5-25 (32\%) and BMI >25(19.3\%). No significant association between reproductive morbidity and presence of co morbidity.

Associated factors of reproductive morbidity on univariate and multivariate analysis is given in the table number $4 \& 5$. 
Treatment seeking behavior: Among the diseased, 145 women (79.2\%) took some mode of treatment. All women with obstetric morbidity and contraceptive morbidity took treatment. 38 women (20.8\%) with gynaecological morbidity didn't take any treatment. Among the women who did not avail treatment, majority $20(52.63 \%)$ were shy to reveal the problem and $9(23.8 \%)$ had not perceived the symptoms as a problem. Some of women 7 $(18.42 \%)$ feel that the treatment is not necessary for this problem.

\section{Discussion}

Among the women $42.5 \%$ reported a history of menstrual abnormality within one year of the survey. Most frequently reported problem was dysmenorrhoea. Similar results were observed in other Indian studies Sowmini C V and Sankara sarma $\mathrm{P}$ et al in the year 1999 in a study conducted at Thiruvananthapuram. There was a higher prevalence of the specific menstrual symptoms in this study when compared with Sowmini C V and Sankara sarma P et al [12].

S K Singh, Sourabh singh et al [13] reported that most frequently reported menstrual symptoms were painful periods and scanty bleeding in the study conducted in the rural women of Maharashtra. Monika Rathore, Leela Vyas et al found out that $35 \%$ of the ever married women reported menstrual problems in the study conducted in Jaipur in 2002 [14]. Mulgaonkar, Veena Bet al reprted in 1996 that the prevalence of menstrual disorders was $39 \%$ in a study conducted in urban slum of Bombay [15].

In the study women, $30.5 \%$ reported at least one type of reproductive morbidity within the 3 months of survey. $167(27.8 \%)$ women had gynaecological morbidity, $8(1.3 \%)$ had obstetric morbidity and 8 $(1.3 \%)$ had contraceptive morbidity. Prevalence of the reproductive morbidity was found to be lower than that reported by Sourabh singh et al in Rural Maharashtra in 2006 [12] where the prevalence was $60 \%$ (Varies from $40.2 \%$ to $80.3 \%$ in different districts). The prevalence of gynecological morbidity was similar to that in other studies. The ICMR task force study (1996-97) in 23 districts by Indra $P$. Kambo et al [16] reported a prevalence of $29.1 \%$ in Kerala. The result is also similar to the prevalence of $24.4 \%$ noted by Bhatia JC et al [8] in South India. In a study done in Salem District Tamil nadu ( kannan C Athmaraman et al [17] the prevalence of any one self reported reproductive morbidity was $24 \%$.
Gupta et al [18] showed a prevalence of $22.3 \%$ in Rajastan. Pandit et al [19] reported (2005) in Mumbai slum $73 \%$ of all women had one or more of the gynaecological conditions. Almost 1/3rd, 30\% reported white discharge, 39\% had backache and $21 \%$ abdominal pain, 39\% showed cervicitis).

The commonly reported gynaecological morbidity were reproductive tract infection $63(10.5 \%)$, urinary tract infection $49(8.2 \% 0)$ and stress incontinence $24(4 \%)$. Among the study group $8(1.3 \%)$ had PID, $3(0.5 \%)$ had dysmenorrhoea, $2(0.3 \%)$ had uterine prolapse. In this study $17(2.8 \%)$ women reported with more than syndrome.

The prevalence of RTI is similar to the recent DLHS 3 (2007-08) where $11.9 \%$ of rural women in Kerala has symptoms of RTI but was found to be lower when compared with different studies throughout the country. Bhatia JC [20] et al showed a prevalence of $17.5 \%$ in Karnataka and Monika Rathore [13] et al showed $31.8 \%$ in Rajasthan. Another study by Bashi66 Gash et al showed that $47 \%$ of ever married women reported RTI. Recent studies done in Kolkata by Dasgupta [21] et al also reported a high prevalence of $43.3 \%$ ( 2006).

In this study $16(2.6 \%)$ women had deliveries in the past 3 months and 20 (3.3\%) women were pregnant. Among them, the proportion of women with complications in this study was 8 (22.22\%) which was lower than in other studies. In a study $A$. S. Dey et al [22] reported in 2008 that 63, 43, 48 $\%$ of women experienced pregnancy complications, delivery complications, and post-delivery complications in Madhya Pradesh.

Santhosh Kumar [23] et al (2002) reported the prevalence of pregnancy complication as $34.2 \%$ in India. In Kerala women are well aware about obstetric care and seek the ante natal care earlier and regularly. Hence the morbidity and also mortality is less when compared with other states. More over health facilities are easily accessible to both rural and urban women.

\section{Conclusion}

Reproductive health problems are prevalent in this community. More than one fourth of the women reported at least one type of gynaecological morbidity which is a high prevalence. Socio demographic factors have some role in the prevalence of reproductive morbidity such as age, religion, occupation, housing standards, socio economic status, co habitation status. 
Other risk factors included early age at menarche, early age at marriage, bad obstetric history, increased parity, history of menstrual abnormality and poor nutritional status etc. Even though there is a higher prevalence, the proportion of women seeking the healthcare is comparatively less. In a state like Kerala where the accessibility to the health care facilities are high and people are concerned with health, even then $20 \%$ (not taken any treatment) is not acceptable.

Shyness to reveal the problem still exists in the community. The female literacy of Kerala is high when compared to the other states, but most of the women are unaware regarding the symptoms, signs and complications of reproductive health problems. There is a need for improving awareness and motivation of early treatment seeking behaviour for reproductive morbidities to reduce complication due to such morbidity.

\section{Acknowledgement}

Acknowledge all the participants of in this study

\section{Reference}

01. United Nations Population Division. State of the world population 2005- the promise of equality gender equity, reproductive health and the Millennium Development Goals. NewYorkUNFPA.

Available from: [Article] [Crossref]

02. Bansal K M, Singh K, Bhatnagar S. Prevalence of lower reproductive tract infections among married females in the reproductive age group(15-45). Health Population perceptive Issues. $2001 ; 24 ; 157-63$.

[Crossref]

03. WHO. world health strategy. 2004 WHO/RHR/04.

8 [Crossref]

04. Wilhelmson, and Gerdtham. The World Health Report, Make Every Mother and Child Count. Switzerland, Geneva- WHO. 2006;7. [Crossref]

05. Newsletter of the Department of Reproductive Health and Research of the World Health Organization. WHO. 2001. [Crossref]
06. Report of National family Health Survey 2. 1998-99. .

[Crossref]

07. District Level household Facility Survey 3, 200708, MoHFW, International institute for population sciences, Fact sheet.

[Crossref]

08. Bhatia J C, Cleland T. Bulletin of WHO. 2001;79(11)1065-1069.

[Crossref]

09. Newsletter of the Department of Reproductive Health and Research of the World Health Organization. WHO. 2001.

[Crossref]

10. Pareek U, Trivedi G. Manual of socio-economic status scale (rural). New Delhi, Manasayan Publishers. 1995.

[Crossref]

11. Shaws Text Book of Gynaecology. 12th ed, ch17. .

[Crossref]

12. Sowmini CV, Sankara Sharma, et al. Reproductive morbidity among contraceptive users- Need for quality services. The Journal of Family Welfare. vol-50;No1; June 2004. [Crossref]

13. Singh S, Singh SK, et al. Reproductive Morbidity among the Rural Women in Maharastra. IIPS India. 2006.

Available at: [Article] [Crossref]

14. Monika Rathore, Leela Vyas. Prevalence of Reproductive Tract Infections amongst Ever Married Women and Sociocultural Factors Associated with It. J Indian Med Assoc. 2007; 105; 71-78.

[Crossref]

15. Mulgaonkar Veena B. Reproductive Health of Women in Urban Slums of Bombay. Social Change. 1996;26(3-4)137-156.

[Crossref]

16. Indra $\mathrm{P}$ K, Dhillon BS, et al. Self-Reported Gynecological Problems from Twenty-Three Districts in India (An ICMR Task Force Study). Indian Journal of Community Medicine. Vol-28; No-2(2003-04 - 2003-06).

[Crossref] 
17. Kannan C, Athmaraman TN, Nayeem Abdul, Sangeetha S, Sudha R, Ponsuganthi K, Murugan $\mathrm{K}$, et al. Prevalence of reproductive tract infections among recently married women in Veerapandi Panchayat union of Salem district, Tamil Nadu. Indian Journal of Community Medicine. 2007;32(2)144-145.

[Crossref]

18. Sharma S, Gupta BP, et al. The Prevalence of Reproductive Tract Infections and Sexually Transmitted Diseases Among Married Women in the Reproductive Age Group in a Rural Area. Indian Journal of Community Medicine. 2009;34(1).

[Crossref]

19. D Pandit, et al. Morbidity Pattern of Women Attending Screening Program in an Urban Slum in Mumbai. Indian Journal of Community Medicine. 30;4(2005-10 - 2005-12).

[Crossref]
20. Bhatia JC, Cleland J. Obstetric morbidity in south India- results from a community survey. Soc Sci Med. 1996;43(10)1507-16.

[Crossref]

21. Dasgupta A, Sarkar $M$, et al. A study on reproductive tract infections among married women in the reproductive age group (15-45 years) in a slum of Kolkata. J Obstet Gynecol India. 2008;58(6)518-522.

[Crossref]

22. Dey AS, et al. PRC Research Monograph- Level and Determinants of Reproductive Morbidity in Madhya Pradesh, Population Research Centres, PRC Division. Ministry of Health \& Family Welfare Government of India. 26-8-2009. [Crossref]

23. Gupta SK, Prasad R, et al. Reproductive Morbidity among Currently Married Women in EAG States- Evidence from the Reproductive and Child Health survey 2002-2004. IIPS.

[Crossref] 